\title{
Palladium (0) Nanoparticles: A Novel and Reusable Catalyst for the Synthesis of Various Pyran Derivatives
}

\author{
Mithu Saha, Amarta Kumar Pal \\ ${ }^{1}$ North Eastern Hill University, Department of Chemistry, Mawlai Campus, Shillong, India \\ Email: amartya_pal22@yahoo.com
}

Received September 18, 2012; revised October 25, 2012; accepted November 2, 2012

\begin{abstract}
A ligand free, Palladium nanoparticles catalyzed synthesis of pyran derivatives using C-H activated compound, malononitrile and aryl aldehyde via Knoevenagel condensation followed by Michael addition reaction using Palladium nanoparticles as catalyst in one-pot is described herein. The advantages of this method lie in its simplicity, low catalyst loading, cost effectiveness and easy to handle. The Palladium Nanoparticles can be reused without loss of activity even after recycling four times. The palladium nanoparticles were characterized by powder X-ray diffraction (XRD), transmission electron microscopy (TEM). The present method also allows us to synthesize highly functionalized title compounds from simple and readily available inputs.
\end{abstract}

Keywords: Palladium Nanoparticles; Multi-Component Reaction; Pyran Derivatives; Dimedone; 4-Hydroxy Coumarin; Pyranazolone

\section{Introduction}

Pyran derivatives are of considerable interest in industry as well as in academia owing to their promising biological activity such as anticoagulant, anticancer, diuretic, spasmolytic and anti-anaphylactin agents. [1] Furthermore, recent studies have revealed several medicinal applications such as, for the treatment of alzheimer's disease, Huntington's disease, amyoprophic lateral sclerosis, Parkinson's diseases, AIDS associated dementia and Down's syndrome as well as for the treatment of schizophrenia and myoclonus. [2,3] These heterocycles are also used as cosmetics, pigments and biodegradable agrochemicals and photoactive materials. [4,5] A considerable effort has been made for the synthesis of pyran annulated heterocyclic derivatives due to their wide applications. Recently, a few methods have been reported by using various catalyst e.g: $\beta$-cyclodextrin, [6] TEBA, [7] N-methylmorphine, [8] $\mathrm{Et}_{3} \mathrm{~N},[9] \mathrm{I}_{2}$, [10] organocatalyst, [11] DBU, [12] KF/basic $\mathrm{Al}_{2} \mathrm{O}_{3}$, [13] ionic liquid, [14] $\mathrm{NaBr}$. [15] Although most of these processes offer distinct advantages, but at the same time they suffer from certain drawbacks also such as longer reaction time, unsatisfactory yields, high costs, harsh reaction conditions, use of stoichiometric amounts of catalyst as well as environmentally toxic catalysts. Thus the development of simple, highly efficient methodologies remains desired.

As a part of our interest in this area, we initiated an investigation to explore the potential of metal nanopar- ticles for C-C bond formation. The use of palladium nanoparticles has recently received considerable attention in the synthesis of various important heterocycles. $[16,17]$ These metal nanoparticles exhibit size-induced quantumsize effects (i.e., electron confinement and surface effect) and can be exploited for a number of advanced functional applications such as sensors, electronics and catalysis, [18] In general, the catalytic property of metal nanoparticles are a function of their size, crystal lattice parameters. The development of new catalysts in nanorange has emerged as a fertile field for research and innovation. The ability of nanotechnology to enhance catalytic activity opens the potential to replace expensive catalysts with lower amounts of inexpensive nanocatalysts.

Our literature survey at this stage revealed that, there are no reports yet available on the synthesis of pyrans derivatives in one-pot catalyzed by Pd nanoparticles. In the present work, we report here a novel, ligand-free protocol for synthesis of pyran derivatives catalyzed by palladium(0) nanoparticles.

\section{Experimental}

\subsection{Apparatus}

General. Melting points were determined in open capillaries and are uncorrected. IR spectra were recorded on Spectrum BX FT-IR, Perkin Elmer $\left(v_{\max }\right.$ in $\left.\mathrm{cm}^{-1}\right)$ on $\mathrm{KBr}$ disks. ${ }^{1} \mathrm{H}$ NMR and ${ }^{13} \mathrm{C}$ NMR $(400 \mathrm{MHz}$ and 100 $\mathrm{MHz}$ respectively) spectra were recorded on Bruker 
Avance II-400 spectrometer in $\mathrm{CDCl}_{3}$ (chemical shifts in $\delta$ with TMS as internal standard). Mass spectra were recorded on Waters ZQ-4000. Transmission electron microscope (TEM) was recorded on JEOL JSM 100CX. XRD was recorded on Bruker D8 XRD instrument SWAX. $\mathrm{CHN}$ were recorded on CHN-OS analyzer (Per- kin Elmer 2400, Series II). Silica gel G (E-mark, India) was used for TLC. Hexane refers to the fraction boiling between $60^{\circ} \mathrm{C}$ and $80^{\circ} \mathrm{C}$.

\subsection{Synthesis of Pyran Derivatives (6a-k, 7a-e and 8a-i)}

A mixture of aryl aldehyde (1 mmol), malononitrile (1 mmol) and activated C-H (3, 4 and 5) (1 mmol) was taken in r.b to that palladium chloride $(0.04 \mathrm{mmol})$, tetrabutylammonim bromide $(1 \mathrm{mmol})$ and sodium carbonate $(3 \mathrm{mmol})$ in acetonitrile $(15 \mathrm{~mL})$ was refluxed for the time mention in Table 1. After completion of the reaction monitored by TLC the reaction mixture was cooled, filtered and the solvent was removed under reduced pressure. The residue was extracted ethyl acetate $(3 \times 10 \mathrm{~mL})$ and the combined organic extract was washed with water $(3 \times 10 \mathrm{~mL})$, brine $(10 \mathrm{~mL})$ and dried over anhydrous $\mathrm{Na}_{2} \mathrm{SO}_{4}$. After removing the solvent the crude product was purified by column chromatography over silica gel (60 - 120 mesh) using hexane-ethyl acetate (7:3) mixture as eluent to afford the pure products (6a-k, 7a-e and 8a-i).

Table 1. Synthesis of pyran derivatives under palladium nanoparticles catalyzed condition.

\begin{tabular}{|c|c|c|c|c|c|}
\hline Entry & $\mathrm{Ar}-\mathrm{CHO}$ & Product & Time (h) & Yield (\%) ${ }^{\mathrm{a}}$ & m.p $\left({ }^{\circ} \mathrm{C}\right)$ \\
\hline 1 & $\mathrm{C}_{6} \mathrm{H}_{5}$ & $6 a$ & 5 & 87 & $230-232$ \\
\hline 2 & $4-\mathrm{CH}_{3} \mathrm{C}_{6} \mathrm{H}_{4}$ & $6 b$ & 4.3 & 88 & $215-217$ \\
\hline 3 & $4-\mathrm{OCH}_{3} \mathrm{C}_{6} \mathrm{H}_{4}$ & $6 c$ & 4.3 & 85 & $196-198$ \\
\hline 4 & 4- $\mathrm{FC}_{6} \mathrm{H}_{4}$ & $6 \mathrm{~d}$ & 4 & 89 & $189-191$ \\
\hline 5 & $4-\mathrm{NO}_{2} \mathrm{C}_{6} \mathrm{H}_{4}$ & $6 e$ & 4 & 90 & $174-176$ \\
\hline 6 & $4-\mathrm{BrC}_{6} \mathrm{H}_{4}$ & $6 f$ & 4 & 88 & $195-197$ \\
\hline 7 & 4-N($\left(\mathrm{CH}_{3}\right)_{2} \mathrm{C}_{6} \mathrm{H}_{4}$ & $6 g$ & 5 & 86 & $198-199$ \\
\hline 8 & $4-\mathrm{ClC}_{6} \mathrm{H}_{4}$ & $6 \mathrm{~h}$ & 4.2 & 88 & $213-215$ \\
\hline 9 & $4-\mathrm{CNC}_{6} \mathrm{H}_{4}$ & $6 \mathrm{i}$ & 4 & 87 & $223-225$ \\
\hline 10 & $2-\mathrm{ClC}_{6} \mathrm{H}_{4}$ & $6 \mathbf{j}$ & 4.3 & 89 & $212-213$ \\
\hline 11 & $\mathrm{C}_{10} \mathrm{H}_{10}$ & $6 \mathrm{k}$ & 5 & 90 & $210-211$ \\
\hline 12 & $\mathrm{C}_{6} \mathrm{H}_{5}$ & $7 a$ & 4.5 & 91 & $255-257$ \\
\hline 13 & $4-\mathrm{CH}_{3} \mathrm{C}_{6} \mathrm{H}_{4}$ & $7 \mathrm{~b}$ & 5 & 87 & $256-258$ \\
\hline 14 & $4-\mathrm{NO}_{2} \mathrm{C}_{6} \mathrm{H}_{4}$ & $7 c$ & 4 & 90 & $250-252$ \\
\hline 15 & $4-\mathrm{OCH}_{3} \mathrm{C}_{6} \mathrm{H}_{4}$ & $7 d$ & 4.3 & 86 & $227-229$ \\
\hline 16 & $4-\mathrm{CNC}_{6} \mathrm{H}_{4}$ & $7 e$ & 4 & 91 & $225-226$ \\
\hline 17 & $\mathrm{C}_{6} \mathrm{H}_{5}$ & $8 a$ & 4 & 90 & $167-169$ \\
\hline 18 & $4-\mathrm{CH}_{3} \mathrm{C}_{6} \mathrm{H}_{4}$ & $8 b$ & 4.3 & 90 & $176-178$ \\
\hline 19 & $4-\mathrm{FC}_{6} \mathrm{H}_{4}$ & $8 c$ & 4 & 87 & $170-172$ \\
\hline 20 & $4-\mathrm{NO}_{2} \mathrm{C}_{6} \mathrm{H}_{4}$ & $8 d$ & 4 & 90 & $190-192$ \\
\hline 21 & $4-\mathrm{BrC}_{6} \mathrm{H}_{4}$ & $8 \mathrm{e}$ & 4 & 88 & $181-183$ \\
\hline 22 & 4- $\mathrm{ClC}_{6} \mathrm{H}_{4}$ & $8 f$ & 4 & 86 & $175-177$ \\
\hline 23 & $4-\mathrm{CNC}_{6} \mathrm{H}_{4}$ & $8 g$ & 4.3 & 89 & $195-197$ \\
\hline 24 & $3-\mathrm{NO}_{2} \mathrm{C}_{6} \mathrm{H}_{4}$ & $8 \mathrm{~h}$ & 4.1 & 85 & $189-191$ \\
\hline 25 & $2-\mathrm{ClC}_{6} \mathrm{H}_{4}$ & $8 \mathrm{i}$ & 4.3 & 88 & $190-192$ \\
\hline
\end{tabular}

${ }^{\mathrm{a}}$ Isolated yields. 


\section{Result and Discussion}

As a part of our ongoing interest in the synthesis of biologically relevant heterocyclic compound, $[19,20]$ we had the opportunity to further explore its catalytic activity toward the synthesis of pyran derivatives. Recently it has been proved that Pd (0) nanoparticles as catalyst offer great opportunities for a wide range of application in organic synthesis such as Heck reaction, Suzuki-Miyaura coupling, hydrogenation of olefins and Hiyama crosscoupling. [21-24] To optimize the reaction conditions for the synthesis of pyran derivatives (Scheme 1), condensation of dimedone (1 mmol), benzaldehyde $(1 \mathrm{mmol})$ and malononitrile $(1 \mathrm{mmol})$ in presence of palladium nanoparticles in acetonitrile under refluxing condition was selected as a model reaction and it furnished a white solid product $6 \mathrm{a}$ in $87 \%$ yield. After the completion of the reaction monitored by TLC, the reaction mixture was brought to room temperature, cooled, filtered extracted with ethyl acetate, washed with brine and dried over $\mathrm{Na}_{2} \mathrm{SO}_{4}$. The crude mass was purified by column chromatography. Structure of compound 6a was determined by the analysis of analytical and spectral data. The presence of a singlet at $\delta 4.33$ and broad singlet at $\delta 4.47$ in ${ }^{1} \mathrm{H}$ NMR and picks at 3428, 3321, $2196 \mathrm{~cm}^{-1}$ and 1659 $\mathrm{cm}^{-1}$ in IR spectra clearly indicate the formation of 6 a.
The Pd (0) nanoparticles were generated in situ by the reduction of $\mathrm{PdCl}_{2}$ in presence of tetra butyl ammonium bromide (TBAB) and sodium carbonate $\left(\mathrm{Na}_{2} \mathrm{CO}_{3}\right)$ in acetonitrile under refluxing condition. We assume that, $\mathrm{Pd}^{2+}$ was reduced to zero-valent state due to the transfer of two electron from $\mathrm{Br}^{-}$ion of TBAB. [25-27] The transmission electron microscopy (TEM) (Figure 1) micrograph showed that palladium nanoparticles with an average ranging from of 30 - $40 \mathrm{~nm}$. X-ray diffraction (XRD) of palladium nanoparticles are shown in (Figure 2).

Furthermore, in transition-metal-catalyzed reactions, ligands play a significant role. Numerous phosphine and nonphosphine ligands for palladium are described in the literature for cross-coupling reactions. Several of these ligands are air and moisture sensitive, difficult to prepare, and expensive. Thus, catalysis by a ligand-free metal center is an area of high importance. [28,29] The catalytic system based on metal nanoparticles appears to be a promising area because of the high surface to volume ratio of such particles.

A plausible mechanism for the reaction was depicted in Scheme 2. Pd Nanoparticles increase the electrophilicity of carbonyl carbon of $\mathrm{C}-\mathrm{H}$ activated compounds as well as aryl aldehydes. First aryl aldehydes and malononitrile

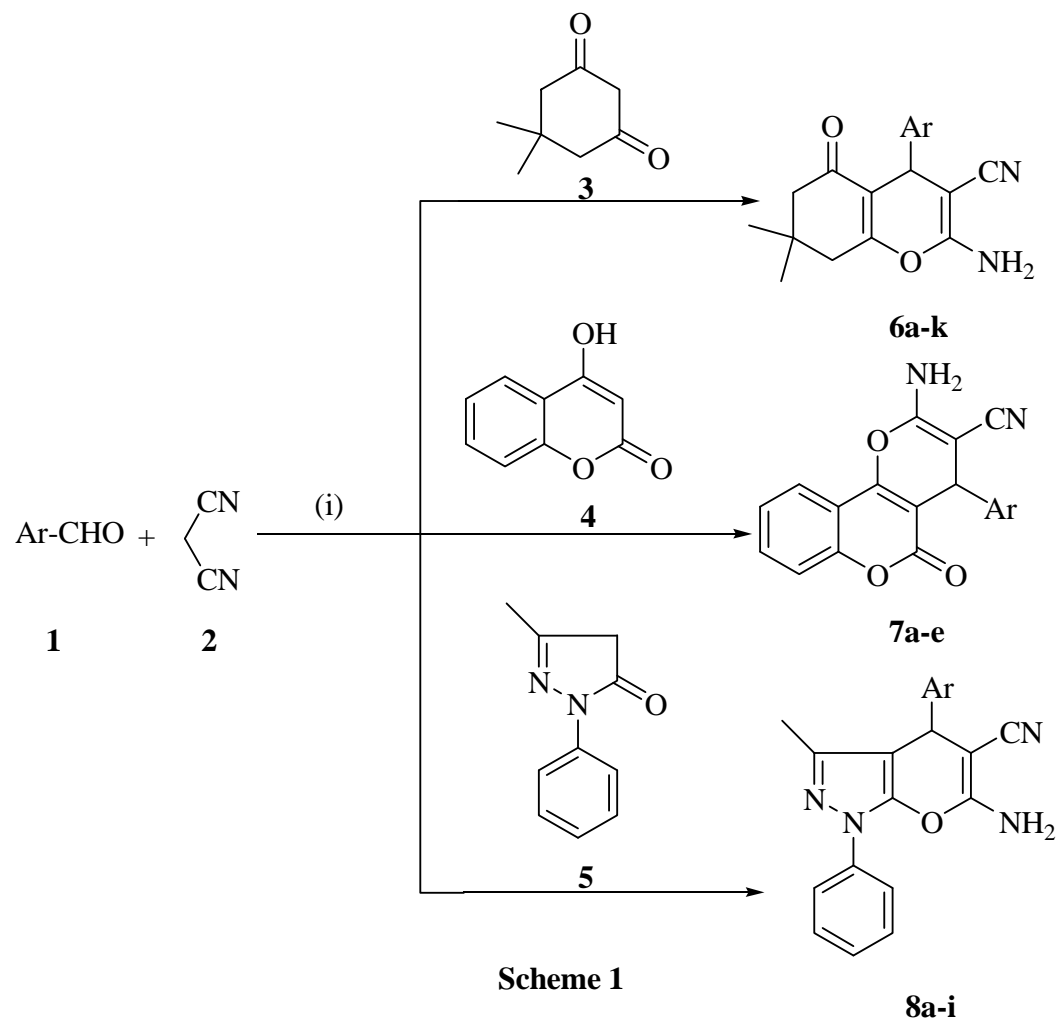

Reagent and Condition: (i) $\mathrm{Pd} \mathrm{Cl}_{2}, \mathrm{Na}_{2} \mathrm{CO}_{3}$, TBAB, acetonitrile, refluxed 4-5 h

Scheme 1. Synthesis of pyran derivatives by using palladium nanoparticles. 


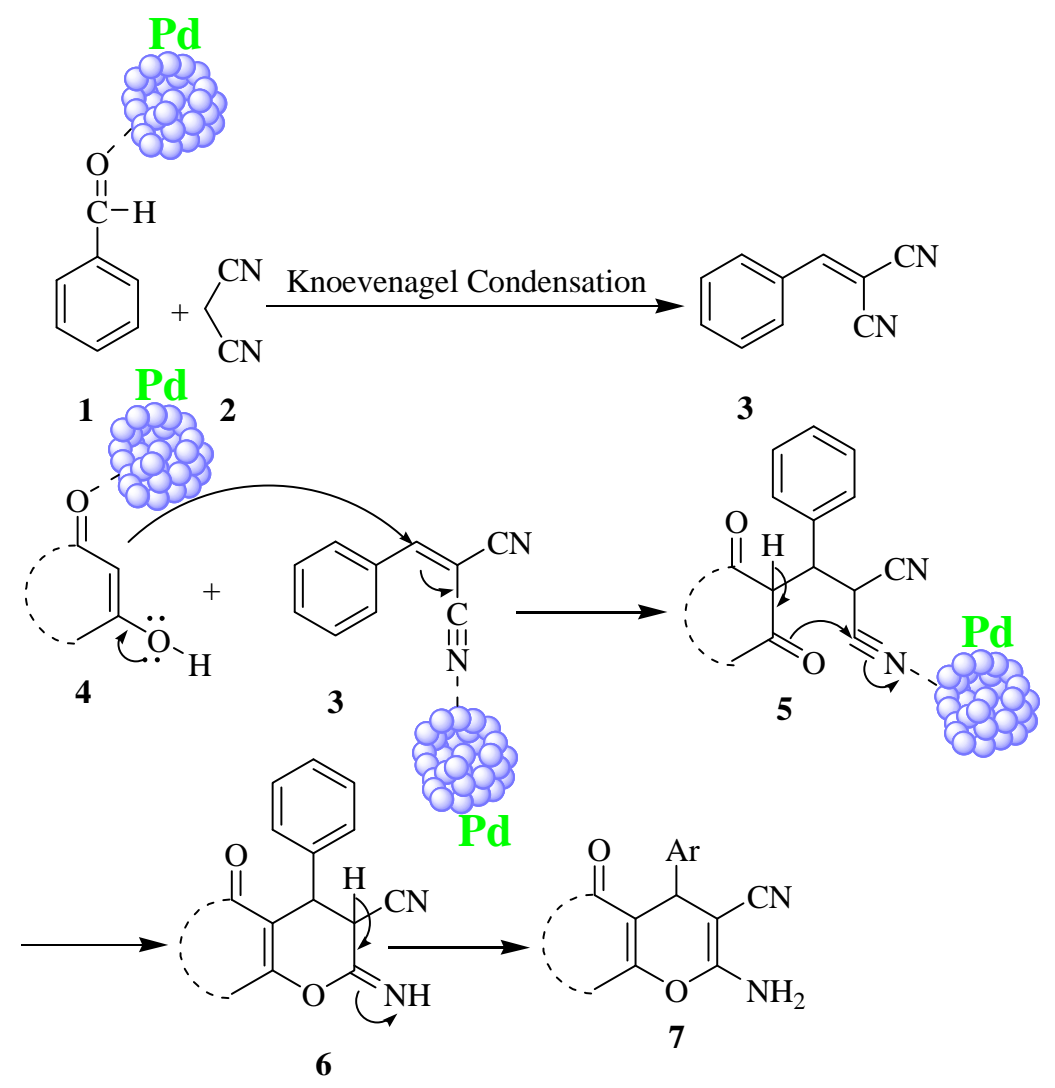

Scheme 2. Plausible reaction mechanism.

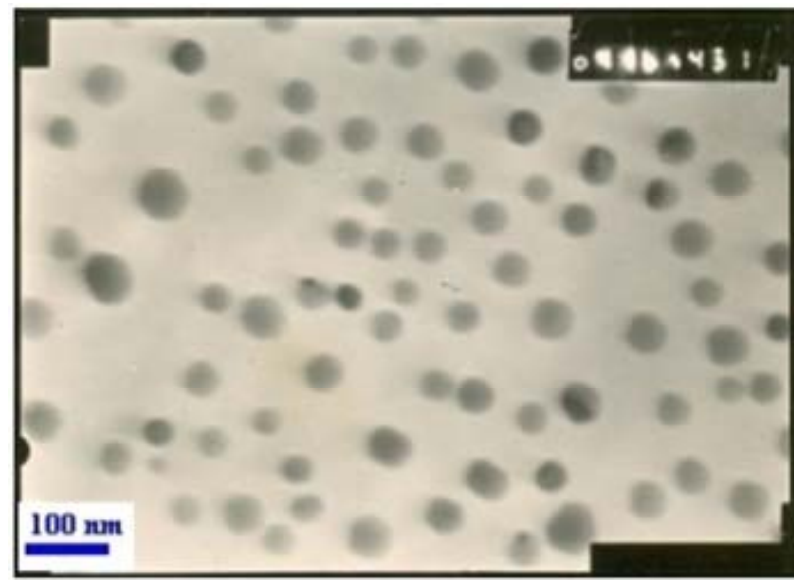

Figure 1. TEM image of palladium nanoparticles.

formed Knoevenagel product 3. Methine carbon of $\mathbf{3}$ is activated by nanoparticles and it react with $\mathrm{C}-\mathrm{H}$ activated compound in a Michael fashion, giving intermediate $\mathbf{5}$. Intermediate $\mathbf{5}$ undergoes intramolecular cyclization followed by tautomerization furnished pyran derivatives 7 .

With these encouraging results, we turn to explore the scope of the present protocol with other $\mathrm{C}-\mathrm{H}$ activated compounds such as 4-hydroxy coumarin or pyrazolone using aryl aldehydes and malononitrile under similar reaction condition (Scheme 1). The components underwent

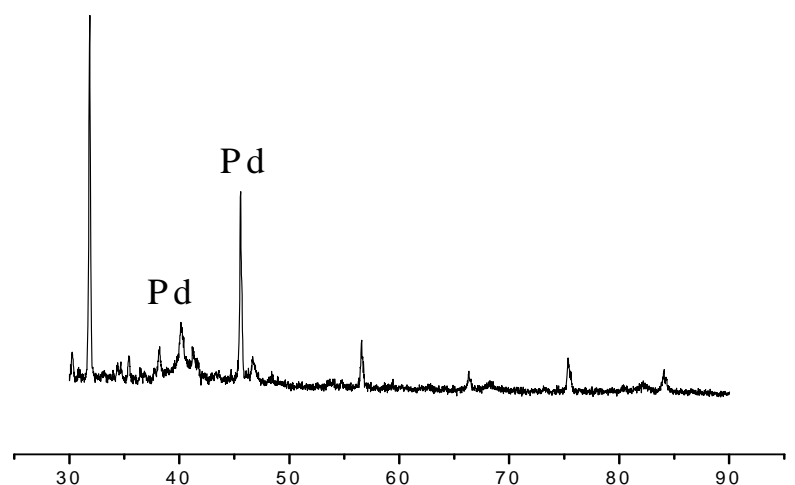

Figure 2. Powder XRD pattern with characteristic dihedral angels at $40.17^{\circ}$ and $45.73^{\circ}$ corresponding to Pd nanoparticles.

successful condensation to give corresponding pyran derivatives in good to excellent yields. The results are summarized in Table 1. From Table 1, it is evident that aromatic aldehydes containing either electron donating or electron withdrawing substituent provided good to excellent yields.

Domino Knoevenagel condensation/Michael addition of dimedone, benzaldehyde and malononitrile using Pd (0) nanoparticles was investigated with various solvents, including water $\left(\mathrm{H}_{2} \mathrm{O}\right)$, dichloromethane (DCM), and 
tetrahydrofuran (THF). Significant improvement was achieved in THF and DCM (Table 2, entries 1 and 2) but the best result was observed when we used acetonitrile was used as a reaction medium (Table 2, entry 5).

We also evaluated the amount of catalyst required for the reaction and we found that yields were obviously affectted by the amount of catalyst loading. We have verified the concentration of catalyst from 0.01 to $0.06 \mathrm{mmol}$. The result revealed that best yield was obtained by using $0.04 \mathrm{mmol}$ catalyst. With increase the catalyst concentration the yield of the desire product was found to be constant. We also carried out the reaction without any catalyst, but the product was isolated in poor yield (16\%), and starting material was recovered. Therefore, the catalyst plays a crucial role in the success of the reaction in term of yields of the product. The results obtained are summarized in Table 3.

For practical application of heterogeneous system, recovery and reusability of the catalyst are very important factors. To clarify this issue, we established a set of experiment using recycled catalyst. The reactions were carried out under similar conditions. After completion of the first set of reaction to afford the corresponding product in $87 \%$ yield. The catalyst was recovered by centrifugation of the reaction mixture at $4000 \mathrm{rpm}$ at room temperature

Table 2. Optimization of solvent effect on the model reaction $^{\mathrm{a}}$.

\begin{tabular}{cccc}
\hline Entry & Solvent $^{\mathrm{b}}$ & $\begin{array}{c}\text { Time } \\
(\mathrm{h})\end{array}$ & $\begin{array}{c}\text { Yield } \\
(\%)^{\mathrm{c}}\end{array}$ \\
\hline 1 & Tetrahydrofuran & 5 & 62 \\
2 & Dichloromethane & 5 & 67 \\
3 & Ethanol & 5 & 53 \\
4 & Water & 5 & 51 \\
5 & Acetonitrile & 5 & 87 \\
\hline
\end{tabular}

${ }^{\mathrm{a}}$ Reaction Conditions: Dimedone (1 mmol), benzaldehyde $(1 \mathrm{mmol})$, malonitrile $(1 \mathrm{mmol})$, and $\mathrm{PdCl}_{2}(0.04 \mathrm{mmol})$, TBAB $(1 \mathrm{mmol}), \mathrm{Na}_{2} \mathrm{CO}_{3}$ (3

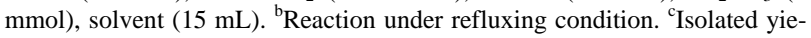
lds.

Table 3. Effect of catalyst loading on the model reaction ${ }^{\text {a }}$

\begin{tabular}{ccccc}
\hline Entry & $\begin{array}{c}\text { Catalyst } \\
(\mathrm{mmol})\end{array}$ & $\begin{array}{c}\text { Temperature } \\
\left({ }^{\circ} \mathrm{C}\right)\end{array}$ & $\begin{array}{c}\text { Time } \\
(\mathrm{h})\end{array}$ & $\begin{array}{c}\text { Yield } \\
(\%)^{\mathrm{b}}\end{array}$ \\
\hline 1 & No catalyst & refluxed & 5 & 16 \\
2 & 0.01 & refluxed & 5 & 33 \\
3 & 0.02 & refluxed & 5 & 52 \\
4 & 0.04 & refluxed & 5 & 87 \\
5 & 0.06 & refluxed & 5 & 87 \\
\hline
\end{tabular}

$\overline{{ }^{a} \text { Reaction Conditions: Dimedone }(1 \mathrm{mmol}) \text {, benzaldehyde (1 mmol), malo- }}$ nitrile (1 mmol), and $\mathrm{PdCl}_{2}(0.04 \mathrm{mmol})$, TBAB (1 mmol), $\mathrm{Na}_{2} \mathrm{CO}_{3}$ (3 $\mathrm{mmol})$, solvent $(15 \mathrm{~mL}){ }^{\mathrm{b}}{ }^{\mathrm{b}}$ Isolated yields.

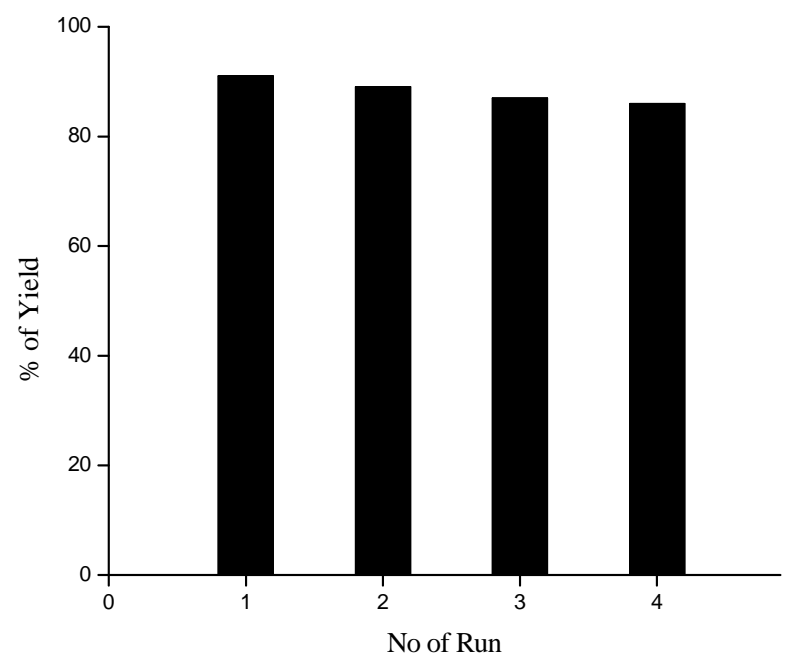

Figure 3. Reusability of the Palladium catalyst.

for 3 - 5 min and filtered, washed and dried. A new reaction was then performed with fresh solvent and reactants under the same condition. To our satisfaction, palladium catalyst could be used at least four times without any noticeable change in activity (Figure 3).

\section{Conclusion}

In conclusion, we have demonstrated a new and efficient methodology for the preparation of pyran derivatives in one-pot procedure using simple and readily available starting materials. Prominent among the advantages of this new method are novelty, low catalyst loading (0.04 mmol), operational simplicity, environmental friendlyness, good yields and reusability of the catalyst.

\section{Acknowledgements}

We thank the Department of Chemistry, Sophisticated Analytical and Instrumentation Facility (SAIF) of NorthEastern Hill University and New Delhi for supporting this work under Special Assistance Programme (SAP). We are also thankful to DST for financial support (sanctioned no: SERC/F/0293/2012-13)

\section{REFERENCES}

[1] L. Bonsignore, G. Loy, D. Secci and A. Calignano, "Synthesis and Pharmacological Activaty of 2-Oxo-(2H)-1benzopyran-3-carboxamide Derivatives," European Journal of Medicinal Chemistry, Vol. 28, No. 6, 1993, pp. 517-520.

[2] W. O. Foye, "Principi Di Chimica farmaceutica," Piccin, Padova, 1991.

[3] L. L. Andreani and E. Lapi, "On Some New Esters of Coumarin-3-carboxylic Acid with Balsamic and Bronchodilator Action," Bollettino chimico farmaceutico, Vol. 99, 1960, pp. 583-586. 
[4] D. Armetso, W. M. Horspool, N. Martin, A. Ramos and C. Seaone, "Synthesis of Cyclobutenes by the Novel Photochemical Ring Contraction of 4-Substituted-2-amino-3,5dicyano-6-phenyl-4H-pyrans," The Journal of Organic Chemistry, Vol. 54, No. 11, 1989, pp. 3069-3072.

[5] E. A. A. Hafez, M. H. Elnagdi, A. G. A. Elagamey and F. M. A. A. Ei-Taweel, "Nitriles in Heterocyclic Synthesis: Novel Synthesis of Benzo[c]coumarin and of Benzo[c] pyrano[3,2-c]quinoline Derivatives," Heterocycles, Vol. 26, 1987, pp. 903-907.

[6] K. Kanagaraj and K. Pitchumani, "Solvent-Free Multicomponent Synthesis of Pyranopyrazoles: Per-6-amino-bcyclodextrin as a Remarkable Catalyst and Host," Tetrahedron Letters, Vol. 51, No. 25, 2010, pp. 3312- 3316. doi:10.1016/j.tetlet.2010.04.087

[7] D. Shi, J. Mou, Q. Zhuang, L. Niu, N, Wu and X. Wang, "Three-Component One-Pot Synthesis of 1,4-Dihydropyrano[2,3-c]pyrazole Derivatives in Aqueous Media,” Synthetic Communications, Vol. 34, No. 24, 2004, pp. 45574563. doi:10.1081/SCC-200043224

[8] F. Lehmann, M. Holm and S. Laufer, “Three-Component Combinatorial Synthesis of Novel Dihydropyrano[2,3-c] pyrazoles," Journal of Combinatorial Chemistry, Vol. 10, No. 3, 2008, pp. 364-367. doi:10.1021/cc800028m

[9] G. Vasuki, K. Kumaravel, "Rapid Four-Component Reactions in Water: Synthesis of Pyranopyrazoles," Tetrahedron Letters, Vol.49, No. 39, 2008, pp. 5636-5638. doi:10.1016/j.tetlet.2008.07.055

[10] R. S. Bhosale, C. V. Magar, K. S. Solanke, S. B. Mane, S. S. Choudhary and R. P. Pawar, "Molecular Iodine: An Efficient Catalyst for the Synthesis of Tetrahydrobenzo[b] pyrans,” Synthetic Communications, Vol. 37, No. 24, 2007, pp. 4353- 4357. doi:10.1080/00397910701578578

[11] S. Muramulla and C.-G. Zhao, “A New Catalytic Mode of the Modularly Designed Organocatalysts (MDOs): Enantioselective Synthesis of Dihydropyrano[2,3-c]pyrazole," Tetrahedron Letters, Vol. 52, No. 30, 2011, pp. 39053908. doi:10.1016/j.tetlet.2011.05.092

[12] J. M. Khurana, B. Nand and P. Saluja, "DBU: A Highly Efficient Catalyst for One-Pot Synthesis of Substituted 3,4-Dihydropyrano[3,2-c]chromenes, Dihydropyrano[4,3b]pyranes, 2-Amino-4hbenzo[h]chromenes and 2-Amino4H Benzo[g]chromenes in Aqueous Medium," Tetrahedron Letters, Vol. 66, 2010, pp. 5637-5641. doi:10.1016/j.tet.2010.05.082

[13] J.-T. Li, W.-Z. Xu, L.-C. Yang and T.-S. Li, "One-Pot Synthesis of 2-Amino-4-aryl-3-carbalkoxy-7,7-dimethyl5,6,7,8-tetrahydrobenzo[b]pyran Derivatives Catalyzed by KF/Basic $\mathrm{Al}_{2} \mathrm{O}_{3}$ under Ultrasound Irradiation,” Synthetic Communications, Vol. 34, No. 24, 2004, pp. 45654571. doi:10.1081/SCC-200043233

[14] X.-S. Wang, M.-M. Zhang, H. Jiang, C.-S. Yao and S.-J. $\mathrm{Tu}$, "Three-Component Green Synthesis of N-Arylquinoline Derivativesin Ionic Liquid $[\mathrm{BmimD}]\left[\mathrm{BF}_{4} \mathrm{~L}\right]$ : Reactions of Arylaldehyde,3-arylamino-5,5-dimethylcyclohex2-enone, and Activemethylene Compounds," Tetrahedron, Vol. 63, No. 21, 2007, pp. 4439-4449. doi:10.1016/j.tet.2007.03.068

[15] I. Devi and P. J. Bhuyan, "Sodium Bromide Catalysed One-Pot Synthesis of Tetrahydrobenzo[B]Pyrans via a
Three-Component Cyclocondensation under Microwave Irradiation and Solvent Free Conditions," Tetrahedron Letters, Vol. 45, No. 47, 2004, pp. 8625-8627. doi:10.1016/j.tetlet.2004.09.158

[16] V. Calo, A. Nacci, A. Monopoli and F. Montingelli, "Pd Nanoparticles as Efficient Catalysts for Suzuki and Stille Coupling Reactions of Aryl Halides in Ionic Liquids," The Journal of Organic Chemistry, Vol. 70, 2005, pp. 6040-6044.

[17] B. Baruwati, D. Guin and S. V. Manorama, "Pd on Surface-Modified $\mathrm{NiFe}_{2} \mathrm{O}_{4}$ Nanoparticles: A Magnetically Recoverable Catalyst for Suzuki and Heck Reactions," Organic Letters, Vol. 9, No. 26, 2007, pp. 5377-5380. doi:10.1021/ol702064x

[18] J.-U. Park, J. Heon Lee, U. Paik, Y. Lu and J. A. Rogers, "Nanoscale Patterns of OligonucleotidesFormed by Electrohydrodynamic Jet Printing with Applications in Biosensing and Nanomaterials Assembly," Nano Letters, Vol. 8, No. 12, 2008, pp. 4210-4216. doi:10.1021/nl801832v

[19] M. Saha and A. K. Pal, "Palladium(0) Nanoparticles: An Efficient Catalyst for the One-Pot Synthesis of Polyhydroquinolines,” Tetrahedron Letters, Vol. 52, No. 38, 2011, pp. 4872-4877. doi:10.1016/j.tetlet.2011.07.031

[20] M. Saha, S. A. K. Pal and S. Nandi, "Pd (0) NPs: A Novel and Reusable Catalyst for the Synthesis of bis(heterocyclyl) methanes in Water," RSC Advance, Vol. 2, No. 16, 2012, pp. 6397-6400. doi:10.1039/c2ra20445b

[21] T. M. Razler, Y. Hsiao, F. Qian, R. Fu, R. K. Khan and W. Doubleday, “A Preparatively Convenient Ligand-Free Catalytic PEG 2000 Suzuki-Miyaura Coupling” The Journal of Organic Chemistry, Vol. 74, No. 3, 2009, pp. 1381-1384. doi:10.1021/jo802277z

[22] Z. Zhang, Z. Zha, C. Gan, C. Pan, Y. Zhou, Z. Wang and M.-M. Zhou, "Catalysis and Regioselectivity of the Aqueous Heck Reaction by $\operatorname{Pd}(0)$ Nanoparticles under Ultrasonic Irradiation,” The Journal of Organic Chemistry, Vol. 71, No. 11, 2006, pp. 4339-4342. doi:10.1021/jo060372b

[23] N. Semagina, A. Renken, D. Laub and L. Kiwi-Minsker, "Synthesis of Monodispersed Palladium Nanoparticles to Study Structure Sensitivity of Solvent-Free Selective Hydrogenation of 2-Methyl-3-butyn-2-ol," Journal of Catalysis, Vol. 246, No. 2, 2007, pp. 308-314. doi:10.1016/j.jcat.2006.12.011

[24] D. Srimani, A. Bej and A. Sarkar, "Palladium Nano- particle Catalyzed Hiyama Coupling Reaction of Benzyl Halides," The Journal of Organic Chemistry, Vol. 75, No. 12, pp. 4296-4299. doi:10.1021/jo1003373

[25] M. T. Reetz and M. Maase, "Redox-Controlled SizeSelective Fabrication of Nanostructured Transition Metal Colloids,” Advanced Materials, Vol. 11, No. 9, 1999, pp. 773-777.

[26] M. T. Reetz and E. Westermann, "Phosphane-Free Palladium-Catalyzed Coupling Reactions: The Decisive Role of Pd Nanoparticles," Angewandte Chemie International Edition, Vol. 39, No. 1, 2000, pp. 165-168.

[27] L. Adak, K. Chattopadhyay and B. C. Ranu, "Palladium Nanoparticle-Catalyzed C-N Bond Formation. A Highly 
Regio- and Stereoselective Allylic Amination by Allyl Acetates," The Journal of Organic Chemistry, Vol. 74, No. 10, 2009, pp. 3982-3985. doi:10.1021/j09003037

[28] R. M. Crooks, M. Zhao, L. Sun, V. Chechik and L. K. Yeung, "Dendrimer-Encapsulated Metal Nanoparticles: Synthesis, Characterization, and Applications to Catalysis," Accounts of Chemical Research, Vol. 34, No. 3,
2001, pp. 181-190. doi:10.1021/ar000110a

[29] M. Moreno-Manas and R. Pleixats, "Formation of Carbon-Carbon Bonds under Catalysis by Transition- Metal Nanoparticles," Accounts of Chemical Research, Vol. 36, No. 8, 2003, pp. 638-643. doi:10.1021/ar020267y 


\section{Supporting Information}

1). 2-amino-5,6,7,8-tetrahydro-7,7-dimethyl-5-oxo-4phenyl-4H-chromene-3-carbonitrile (6a)

IR (KBr): 3428, 3371, 2196, 1659, $1613 \mathrm{~cm}^{-1} .{ }^{1} \mathrm{H}$ NMR ( $\left.\mathrm{CDCl}_{3}, 400 \mathrm{MHz}\right): \delta=7.23-7.10(\mathrm{~m}, 5 \mathrm{H}), 4.47$ (s, 2H), 4.33 (s, 1H), 2.38 (s, 2H), $2.10-2.20$ (m, 2H), 1.04 (s, 3H), 0.97 (s, 3H). ${ }^{13} \mathrm{C} \mathrm{NMR}\left(\mathrm{CDCl}_{3}, 100 \mathrm{MHz}\right)$ : $\delta=195.8,161.5,157.4,143.1,128.5,127.5,127.1,118.6$, 114.0, 63.5, 50.6, 40.6, 35.5, 32.2, 28.8, 27.6. ESI-MS $\mathrm{m} / \mathrm{z} 295[\mathrm{M}+\mathrm{H}]^{+}$. Anal calcd for $\mathrm{C}_{18} \mathrm{H}_{18} \mathrm{~N}_{2} \mathrm{O}_{2}$ : C, 73.45; H, 6.16; N, 9.52. Found: C, 73.34; H, 6.13; N, 9.64.

2). 2-amino-5,6,7,8-tetrahydro-7,7-dimethyl-5-oxo-4p-tolyl-4H-chromene-3-carbonitrile (6b)

IR (KBr): 3429, 3330, 2395, 2190, 1679, $1600 \mathrm{~cm}^{-1}$. ${ }^{1} \mathrm{H}$ NMR $\left(\mathrm{CDCl}_{3}, 400 \mathrm{MHz}\right): \delta=7.05-7.00(\mathrm{~m}, 4 \mathrm{H})$, 4.45 (s, 2H), 4.29 (s, 1H), 2.37 (s, 2H), 2.21 (s, 3H), 2.15 (d, J = $5.6 \mathrm{~Hz}, 2 \mathrm{H}), 1.03$ (s, 3H), 0.97 (s, 3H). ${ }^{13} \mathrm{C}$ NMR $\left(\mathrm{CDCl}_{3}, 100 \mathrm{MHz}\right): \delta=196.0,161.4,157.3,140.2,136.7$, 129.3, 127.3, 118.7, 114.1, 63.7, 50.6, 40.6, 35.1, 32.2, 28.9, 27.7, 21.0. ESI-MS m/z $309[\mathrm{M}+\mathrm{H}]^{+}$. Anal calcd for $\mathrm{C}_{19} \mathrm{H}_{20} \mathrm{~N}_{2} \mathrm{O}_{2}$ : C, 74.00; H, 6.54; N, 9.08. Found: C, 73.70; H, 6.31; N, 9.02.

3). 2-amino-5,6,7,8-tetrahydro-4-(4-methoxyphenyl)7,7-dimethyl-5-oxo-4-phenyl-4H-chromene-3-carbontrile (6c)

IR (KBr): 3420, 3323, 2335, 2196, 1659, $1606 \mathrm{~cm}^{-1}$. ${ }^{1} \mathrm{H} \mathrm{NMR}\left(\mathrm{CDCl}_{3}, 400 \mathrm{MHz}\right): \delta=7.09(\mathrm{~d}, \mathrm{~J}=8.0 \mathrm{~Hz}, 2 \mathrm{H})$, 6.75 (d, J = 8.4 Hz, 2H), 4.49 (s, 2H), 4.28 (s, 1H), 3.69 (s, 3H), 2.38 (s, 2H), 2.19 - 2.09 (m, 2H) 1.03 (s, 3H), 0.96 (s, 3H). ESI-MS m/z $325[\mathrm{M}+\mathrm{H}]^{+}$. Anal calcd for $\mathrm{C}_{19} \mathrm{H}_{20} \mathrm{~N}_{2} \mathrm{O}_{3}$ : C, 70.35; H, 6.21; N, 8.64. Found: C, 70.53; $\mathrm{H}, 6.09 ; \mathrm{N}, 8.80$

4). 2-amino-5,6,7,8-tetrahydro-4-(4-fluorophenyl)-7,7 -dimethyl-5-oxo-4-phenyl-4H-chromene-3-carbonitrile (6d)

IR (KBr): 3421, 3363, 2316, 2196, 1653, $1600 \mathrm{~cm}^{-1}$. ${ }^{1} \mathrm{H}$ NMR $\left(\mathrm{CDCl}_{3}, 400 \mathrm{MHz}\right): \delta=7.15-7.12(\mathrm{~m}, 2 \mathrm{H})$, 6.92 - 6.88 (m, 2H), 4.49 (s, 2H), 4.33 (s, 1H), 2.38 (s, 2H), $2.20-2.10(\mathrm{~m}, 2 \mathrm{H}), 1.04$ (s, 3H), 0.96 (s, 3H). ESI-MS m/z $313[\mathrm{M}+\mathrm{H}]^{+}$. Anal calcd for $\mathrm{C}_{18} \mathrm{H}_{17} \mathrm{FN}_{2} \mathrm{O}_{2}$ : C, 69.22; H, 5.49; N, 8.97. Found: C, 69.42; H, 5.42; N, 8.88.

5). 2-amino-5,6,7,8-tetrahydro-4-(4-nitrophenyl)-7,7dimethyl-5-oxo-4-phenyl-4H-chromene-3-carbonitrile Compound (6e)

IR (KBr): 3396, 3323, 2448, 2196, 1666, $1600 \mathrm{~cm}^{-1}$. ${ }^{1} \mathrm{H}$ NMR $\left(\mathrm{CDCl}_{3}+\mathrm{DMSO}-\mathrm{d}_{6}, 400 \mathrm{MHz}\right): \delta=8.07(\mathrm{~d}, \mathrm{~J}$ $=8.4 \mathrm{~Hz}, 2 \mathrm{H}), 7.37$ (d, J = $8.4 \mathrm{~Hz}, 2 \mathrm{H}), 6.31(\mathrm{~s}, 2 \mathrm{H})$, 4.38 (s, 1H), 2.44 (s, 2H), $2.21-2.07$ (m, 2H), 1.05 (s, $3 \mathrm{H}), 0.95$ (s, 3H). ESI-MS m/z $340[\mathrm{M}+\mathrm{H}]^{+}$. Anal calcd for $\mathrm{C}_{18} \mathrm{H}_{17} \mathrm{~N}_{3} \mathrm{O}_{4}$ : C, 63.71; $\mathrm{H}, 5.05 ; \mathrm{N}, 12.38$. Found: C, 63.60; H, 5.18; N, 12.29 .

6). 2-amino-5,6,7,8-tetrahydro-4-(4-bromophenyl)7,7-dimethyl-5-oxo-4-phenyl-4H-chromene-3-carbontrile (6f)

IR (KBr): 3390, 3371, 2475, 2196, 1659, $1613 \mathrm{~cm}^{-1}$. ${ }^{1} \mathrm{H} \mathrm{NMR}\left(\mathrm{CDCl}_{3}+\mathrm{DMSO}-\mathrm{d}_{6}, 400 \mathrm{MHz}\right): \delta=7.32(\mathrm{~d}, \mathrm{~J}$ $=8.4 \mathrm{~Hz}, 2 \mathrm{H}), 7.06(\mathrm{~d}, \mathrm{~J}=8.4 \mathrm{~Hz}, 2 \mathrm{H}), 6.14(\mathrm{~s}, 2 \mathrm{H})$, 4.21 (s, 1H), 2.40 (s, 2H), $2.19-2.06(\mathrm{~m}, 2 \mathrm{H}), 1.03$ (s, 3H), 0.94 (s, 3H). ESI-MS m/z 373, $375[\mathrm{M}+\mathrm{H}]^{+}$. Anal calcd for $\mathrm{C}_{18} \mathrm{H}_{17} \mathrm{BrN}_{2} \mathrm{O}_{2}$ : C, 57.92; H, 4.59; N, 7.51. Found: C, 58.11; H, 4.37; N, 7.78.

7). 2-amino-5,6,7,8-tetrahydro-4-((4-dimethylamino) phenyl)-7,7-dimethyl-5-oxo-4-phenyl-4H-chromene-3carbonitrile (6g)

IR (KBr): 3390, 3317, 2300, 2190, 1659, $1606 \mathrm{~cm}^{-1}$. ${ }^{1} \mathrm{H} \mathrm{NMR}\left(\mathrm{CDCl}_{3}, 400 \mathrm{MHz}\right): \delta=7.06(\mathrm{~d}, \mathrm{~J}=8.4 \mathrm{~Hz}, 2 \mathrm{H})$, 6.71 (brs, 2H), 4.43 (s, 2H), 4.26 (s, 1H), 2.86 (s, 6H), 2.36 (s, 2H), 2.15 (d, J = 3.6 Hz, 2H), 1.03 (s, 3H), 0.97 (s, 3H). ESI-MS m/z $338[\mathrm{M}+\mathrm{H}]^{+}$. Anal calcd for $\mathrm{C}_{20} \mathrm{H}_{23} \mathrm{~N}_{3} \mathrm{O}_{2}$ : C, 71.19; $\mathrm{H}, 6.87 ; \mathrm{N}, 12.45$. Found: C, 71.14; H, 7.02; N, 12.33 .

8). 2-amino-5,6,7,8-tetrahydro-4-(4-chlorophenyl)-7,7 -dimethyl-5-oxo-4-phenyl-4H-chromene-3-carbonitrile (6h)

IR (KBr): 3356, 2236, 2196, 1679, $1606 \mathrm{~cm}^{-1} \cdot{ }^{1} \mathrm{H}$ NMR ( $\left.\mathrm{CDCl}_{3}, 400 \mathrm{MHz}\right): \delta=7.20$ (d, J = $\left.8.0 \mathrm{~Hz}, 2 \mathrm{H}\right)$, 7.11 (d, J = 8.4 Hz, 2H), 4.53 (s, 2H), 4.31 (s, 1H), 2.38 (s, 2H), $2.20-2.10$ (m, 2H), 1.04 (s, 3H), 0.95 (s, 3H). ESI-MS m/z 329, $331[\mathrm{M}+\mathrm{H}]^{+}$. Anal calcd for $\mathrm{C}_{18} \mathrm{H}_{17} \mathrm{ClN}_{2} \mathrm{O}_{2}$ : C, 65.75; $\mathrm{H}, 5.21 ; \mathrm{N}$, 8.52. Found: C, 65.64; H, 5.23; N, 8.58.

9). 2-amino-5,6,7,8-tetrahydro-4-(4-cyanophenyl)-7,7 -dimethyl-5-oxo-4-phenyl-4H-chromene-3-carbonitrile (6i)

IR (KBr): 3390, 2350, 2190, 1672, $1639 \mathrm{~cm}^{-1} \cdot{ }^{1} \mathrm{H}$ NMR $\left(\mathrm{CDCl}_{3}, 400 \mathrm{MHz}\right): \delta=7.54(\mathrm{~d}, \mathrm{~J}=8.0 \mathrm{~Hz}, 2 \mathrm{H})$, 7.30 (d, J = $8.0 \mathrm{~Hz}, 2 \mathrm{H}), 4.61$ (s, 2H), 4.38 (s, 1H), 2.40 (s, 2H), $2.21-2.10$ (m, 2H), 1.05 (s, 3H), 0.95 (s, 3H). ESI-MS m/z $320[\mathrm{M}+\mathrm{H}]^{+}$. Anal calcd for $\mathrm{C}_{19} \mathrm{H}_{17} \mathrm{~N}_{3} \mathrm{O}_{2}$ : C, 71.46; H, 5.37; N, 13.16. Found: C, 71.65; H, 5.40; N, 13.37.

10). 2-amino-5,6,7,8-tetrahydro-4-(2-chlorophenyl)7,7-dimethyl-5-oxo-4-phenyl-4H-chromene-3-carbontrile (6j)

IR (KBr): $\mathrm{cm}^{-1} \cdot{ }^{1} \mathrm{H} \mathrm{NMR}\left(\mathrm{CDCl}_{3}, 400 \mathrm{MHz}\right): \delta=7.26$ - 7.05 (m, 4H), 4.78 (s, 1H), 4.56 (s, 2H), 2.38 (s, 2H), 2.19 - 2.05 (m, 2H), 1.04 (s, 3H), 0.99 (s, 3H). ESI-MS $\mathrm{m} / \mathrm{z} 329,331[\mathrm{M}+\mathrm{H}]^{+}$. Anal calcd for $\mathrm{C}_{18} \mathrm{H}_{17} \mathrm{ClN}_{2} \mathrm{O}_{2}$ : C, 65.75; H, 5.21; N, 8.52. Found: C, 65.57; H, 5.46; N, 8.45 .

11). 2-amino-5,6,7,8-tetrahydro-4-(naphthalene-1-yl) 7,7-dimethyl-5-oxo-4-phenyl-4H-chromene-3-carbontrile (6k)

IR (KBr): 3317, 2380, 2183, 1659, $1593 \mathrm{~cm}^{-1} \cdot{ }^{1} \mathrm{H}$ NMR $\left(\mathrm{CDCl}_{3}, 400 \mathrm{MHz}\right): \delta=8.31(\mathrm{~d}, \mathrm{~J}=8.4 \mathrm{~Hz}, 1 \mathrm{H})$, 7.76 (d, J = 8.0 Hz, 1H), 7.65 (d, J = 8.4 Hz, 1H), 7.51 (t, $\mathrm{J}=7.6 \mathrm{~Hz}, 1 \mathrm{H}), 7.42(\mathrm{t}, \mathrm{J}=7.4 \mathrm{~Hz}, 1 \mathrm{H}), 7.33(\mathrm{t}, \mathrm{J}=7.8$ 
Hz, 1H), 7.17 (t, J = 7.2 Hz, 1H), 5.19 (s, 1H), 4.46 (s, 2H), 2.50 - 2.39 (m, 2H), 2.18 - 2.07 (m, 2H), 1.05 (s, 3H), 0.99 (s, 3H). ESI-MS m/z $345[\mathrm{M}+\mathrm{H}]^{+}$. Anal calcd for $\mathrm{C}_{22} \mathrm{H}_{20} \mathrm{~N}_{2} \mathrm{O}_{2}$ : C, 76.72; $\mathrm{H}, 5.85$; $\mathrm{N}, 8.13$. Found: C, 76.64; H, 5.91; N, 7.96.

12). 2-amino-4,5-dihydro-5-oxo-4-phenylpyrano[3,2c]chromene-3-carbonitrile (7a)

IR (KBr): 3328, 2196, 1712, 1672, $1613 \mathrm{~cm}^{-1} .{ }^{1} \mathrm{H}$ NMR $\left(\mathrm{CDCl}_{3}+\mathrm{DMSO}-\mathrm{d}_{6}, 400 \mathrm{MHz}\right): \delta=7.88-7.11$ (m, 9H), 4.43 (s, 1H), 3.22 (brs, 2H). ESI-MS m/z 317 $[\mathrm{M}+\mathrm{H}]^{+}$. Anal calcd for: $\mathrm{C}_{19} \mathrm{H}_{12} \mathrm{~N}_{2} \mathrm{O}_{3}$ : C, 72.15; $\mathrm{H}, 3.82$; N, 8.86. Found: C, 72.04; H, 3.68; N, 8.80.

13). 2-amino-4,5-dihydro-5-oxo-4-p-tolylpyrano[3,2c]chromene-3-carbonitrile (7b)

IR (KBr): 3396, 2203, 1712, $1606 \mathrm{~cm}^{-1}$. ${ }^{1} \mathrm{H}$ NMR $\left(\mathrm{CDCl}_{3}+\mathrm{DMSO}-\mathrm{d}_{6}, 400 \mathrm{MHz}\right): \delta=7.85-6.99(\mathrm{~m}$, $8 \mathrm{H}), 4.40$ (s, 1H), 3.20 (brs, 2H), 2.20 (s, 3H). ESI-MS $\mathrm{m} / \mathrm{z} 331[\mathrm{M}+\mathrm{H}]^{+}$. Anal calcd for: $\mathrm{C}_{20} \mathrm{H}_{14} \mathrm{~N}_{2} \mathrm{O}_{3}$ : C, 72.72; H, 4.27; N, 8.48. Found: C, 72.91; H, 4.36; N, 8.75.

14). 2-amino-4,5-dihydro4-4(4-nitrophenyl)-5-oxo-4phenylpyrano[3,2-c]chromene-3-carbonitrile (7c)

IR (KBr): 3476, 2196, 1719, $1613 \mathrm{~cm}^{-1}$. ${ }^{1} \mathrm{H}$ NMR $\left(\mathrm{CDCl}_{3}+\mathrm{DMSO}-\mathrm{d}_{6}, 400 \mathrm{MHz}\right): \delta=8.07-7.23(\mathrm{~m}$, $8 \mathrm{H}), 4.60$ (s, 1H), 3.11 (brs, $2 \mathrm{H}) .{ }^{13} \mathrm{C} \mathrm{NMR}\left(\mathrm{CDCl}_{3}+\right.$ DMSO - $\left.\mathrm{d}_{6}, 100 \mathrm{MHz}\right): \delta=164.9,163.3,159.1,157.3$, $154.7,151.7,137.8,133.7,129.5,128.5,127.7,123.6$, 121.4, 117.7, 107.9, 62.5, 41.9. ESI-MS m/z $362[\mathrm{M}+$ $\mathrm{H}]^{+}$. Anal calcd for: $\mathrm{C}_{19} \mathrm{H}_{11} \mathrm{~N}_{3} \mathrm{O}_{5}: \mathrm{C}, 63.16 ; \mathrm{H}, 3.07 ; \mathrm{N}$, 11.63. Found: C, 62.87; H, 2.93; N, 11.54.

15). 2-amino-4,5-dihydro4-4(4-methoxyphenyl)-5-oxo-4-phenylpyrano[3,2-c]chromene-3-carbonitrile (7d)

IR (KBr): 3396, 2196, 1710, $1605 \mathrm{~cm}^{-1} \cdot{ }^{1} \mathrm{H}$ NMR $\left(\mathrm{CDCl}_{3}+\mathrm{DMSO}-\mathrm{d}_{6}, 400 \mathrm{MHz}\right): \delta=7.87-6.72(\mathrm{~m}$, 8H), 6.62 (brs, 2H), 4.42 (s, 1H), 3.69 (s, 3H). ESI-MS $\mathrm{m} / \mathrm{z} 347[\mathrm{M}+\mathrm{H}]^{+}$. Anal calcd for: $\mathrm{C}_{20} \mathrm{H}_{14} \mathrm{~N}_{2} \mathrm{O}_{4}$ : C, 69.36; H, 4.07; N, 8.09. Found: C, 69.55; H, 4.10; N, 8.30.

16). 2-amino-4,5-dihydro4-4(4-cyanophenyl)-5-oxo-4 -phenylpyrano[3,2-c]chromene-3-carbonitrile (7e)

IR (KBr): 3421, 2201, 1712, $1614 \mathrm{~cm}^{-1} .{ }^{1} \mathrm{H}$ NMR $\left(\mathrm{CDCl}_{3}+\mathrm{DMSO}-\mathrm{d}_{6}, 400 \mathrm{MHz}\right): \delta=7.89-7.26(\mathrm{~m}$, 8H), 6.92 (brs, 2H), 4.56(s, 1H). ESI-MS m/z 342 [M + $\mathrm{H}]^{+}$. Anal calcd for: $\mathrm{C}_{20} \mathrm{H}_{11} \mathrm{~N}_{3} \mathrm{O}_{3}$ : C, 70.38; $\mathrm{H}, 3.25 ; \mathrm{N}$, 12.31. Found: C, 70.33; H, 3.37; N, 12.47.

17). 6-amino-1,4-dihydro-3-methyl-1,4-diphenylpyrano[2,3-c]pyrazole-5-carbonitrile (8a)

IR (KBr): 3476, 3330, 2196, $1659 \mathrm{~cm}^{-1}$. ${ }^{1} \mathrm{H}$ NMR (DMSO $\left.-\mathrm{d}_{6}, 400 \mathrm{MHz}\right): \delta=1.76$ (s, 3H), 3.27 (brs, 2H), 4.67 (s, 1H), 7.21 - 7.50 (m, 8H), 7.76 (d, J = 8.0 Hz, 2H). ESI-MS m/z $329[\mathrm{M}+\mathrm{H}]^{+}$. Anal calcd for: $\mathrm{C}_{20} \mathrm{H}_{16} \mathrm{~N}_{4} \mathrm{O}$ : C, 73.15; H, 4.91; N, 17.06. Found: C, 73.02; H, 4.82; N, 16.91 .

18). 6-amino-1,4-dihydro-3-methyl-phenyl-4-p-tolylpyrano[2,3-c]pyrazole-5-carbonitrile (8b)

IR (KBr): 3475, 3326, 2196, $1656 \mathrm{~cm}^{-1}$. ${ }^{1} \mathrm{H}$ NMR
$\left(\mathrm{CDCl}_{3}+\mathrm{DMSO}-\mathrm{d}_{6}, 400 \mathrm{MHz}\right): \delta=1.78$ (s, 3H), 2.25 (s, 3H), 4.50 (s, 1H), 6.22 (s, 2H), 7.35 (t, J = $7.8 \mathrm{~Hz}$, $5 \mathrm{H}), 7.65$ (d, J = 8.4 Hz, 4H). ${ }^{13} \mathrm{C} \mathrm{NMR}\left(\mathrm{CDCl}_{3}+\mathrm{DMSO}\right.$ $\left.-\mathrm{d}_{6}, 100 \mathrm{MHz}\right): \delta=12.4,20.6,36.6,60.1,98.1,119.7$, 120.2, 125.8, 127.3, 128.7, 128.8, 136.2, 137.3, 139.5, 143.6, 145.6, 158.9. ESI-MS m/z $343[\mathrm{M}+\mathrm{H}]^{+}$. Anal calcd for $\mathrm{C}_{21} \mathrm{H}_{18} \mathrm{~N}_{4} \mathrm{O}$ : C, 73.67; H, 5.30; N, 16.36. Found: C, 73.75; H, 5.36; N, 16.48 .

19). 6-amino-4-(4-flurophenyl)-1,4-dihydro-3-methyl -1-phenylpyrano[2,3-c]pyrazole-5-carbonitrile (8c)

IR (KBr): 3420, 3310, 2196, $1666 \mathrm{~cm}^{-1}$. ${ }^{1} \mathrm{H}$ NMR $\left(\mathrm{CDCl}_{3}+\mathrm{DMSO}-\mathrm{d}_{6}, 400 \mathrm{MHz}\right): \delta=1.81(\mathrm{~S}, 3 \mathrm{H}), 4.60$ (s, 1H), 4.64 (brs, 2H), $6.95-7.42$ (m, 7H), 7.56 (d, J = $8.0 \mathrm{~Hz}, 2 \mathrm{H})$. ESI-MS m/z $347[\mathrm{M}+\mathrm{H}]^{+}$. Anal calcd for $\mathrm{C}_{20} \mathrm{H}_{15} \mathrm{FN}_{4} \mathrm{O}$ : C, 69.37; H, 4.37; N, 16.18 Found: C, 69.29; H, 4.48; N, 16.04.

20). 6-amino-4-(4-nitrophenyl)-1,4-dihydro-3-methyl1-phenylpyrano[2,3-c]pyrazole-5-carbonitrile (8d)

IR (KBr): 3400, 3320, 2230, $1658 \mathrm{~cm}^{-1} .{ }^{1} \mathrm{H}$ NMR $\left(\mathrm{CDCl}_{3}+\mathrm{DMSO}-\mathrm{d}_{6}, 400 \mathrm{MHz}\right): \delta=1.78(\mathrm{~S}, 3 \mathrm{H}), 4.74$ (s, 1H), 6.89 (brs, 2H), 7.21 (t, J = 7.4 Hz, 1H), 7.38 7.45 (m, 4H), 7.70 (d, J = 8.0 Hz, 2H), 8.13 (d, J = 8.8 $\mathrm{Hz}, 2 \mathrm{H}) .{ }^{13} \mathrm{C} \mathrm{NMR}\left(\mathrm{CDCl}_{3}+\mathrm{DMSO}-\mathrm{d}_{6}, 100 \mathrm{MHz}\right): \delta$ $=12.5,36.8,57.4,96.9,119.4,120.1,123.5,125.9$, 128.6, 128.8, 137.2, 143.9, 145.1, 146.5, 150.3, 159.5. ESI-MS m/z $374\left[\mathrm{M}+\mathrm{H}^{+}\right.$. Anal calcd for $\mathrm{C}_{20} \mathrm{H}_{15} \mathrm{~N}_{5} \mathrm{O}_{3}$ : C, 64.08; H, 4.05; N, 18.76. Found: C, 64.23; H, 4.19; N, 18.67.

21). 6-amino-4-(4-bromophenyl)-1,4-dihydro-3methyl-1-phenylpyrano[2,3-c]pyrazole-5-carbonitrile (8e)

IR (KBr): 3456, 3330, 2196, $1666 \mathrm{~cm}^{-1}$. ${ }^{1} \mathrm{H}$ NMR $\left(\mathrm{CDCl}_{3}+\mathrm{DMSO}-\mathrm{d}_{6}, 400 \mathrm{MHz}\right): \delta=1.81(\mathrm{~s}, 3 \mathrm{H}), 4.55$ (s, 2H), 5.96 (brs, 2H), 7.07 (d, J = 8.4 Hz, 2H), 7.21 (t, J $=7.2 \mathrm{~Hz}, 1 \mathrm{H}), 7.37-7.41(\mathrm{~m}, 4 \mathrm{H}), 7.63(\mathrm{~d}, \mathrm{~J}=8.0 \mathrm{~Hz}$, 2H). ESI-MS m/z 407, $409[\mathrm{M}+\mathrm{H}]^{+}$. Anal calcd for $\mathrm{C}_{20} \mathrm{H}_{15} \mathrm{BrN}_{4} \mathrm{O}$ : C, 58.98; H, 3.71; N, 13.76. Found: C, 59.06; H, 3.74; N, 13.78.

22). 6-amino-4-(4-chlorophenyl)-1,4-dihydro-3-methyl-1-phenylpyrano[2,3-c]pyrazole-5-carbonitrile (8f)

IR (KBr): 3456, 3370, 2230, $1660 \mathrm{~cm}^{-1} .{ }^{1} \mathrm{H}$ NMR $\left(\mathrm{CDCl}_{3}, 400 \mathrm{MHz}\right): \delta=1.82(\mathrm{~s}, 3 \mathrm{H}), 4.58(\mathrm{~s}, 1 \mathrm{H}), 4.66$ (brs, 2H), 7.12 (d, J = 8.4 Hz, 2H), 7.25 (d, J = 8.4 Hz, 2H), 7.38 (t, J = $7.4 \mathrm{~Hz}, 3 \mathrm{H}), 7.56$ (d, J = $8.0 \mathrm{~Hz}, 2 \mathrm{H})$. ESI-MS m/z 363, $365[\mathrm{M}+\mathrm{H}]^{+}$. Anal calcd for $\mathrm{C}_{20} \mathrm{H}_{15} \mathrm{ClN}_{4} \mathrm{O}$ : C, 66.21; H, 4.17; N, 15.44. Found: C, 65.92; H, 4.24; N, 15.57.

23). 6-amino-4-(4-cyanophenyl)-1,4-dihydro-3- methyl-1-phenylpyrano[2,3-c]pyrazole-5-carbonitrile (8g)

IR (KBr): 3429, 3400, 2369, $1653 \mathrm{~cm}^{-1} .{ }^{1} \mathrm{H}$ NMR $\left(\mathrm{CDCl}_{3}+\mathrm{DMSO}-\mathrm{d}_{6}, 400 \mathrm{MHz}\right): \delta=1.81(\mathrm{~s}, 3 \mathrm{H}), 4.67$ (s, 1H), 4.74 (brs, 2H), 7.25 - 7.61 (m, 9H). ESI-MS m/z $354[\mathrm{M}+\mathrm{H}]^{+}$. Anal calcd for $\mathrm{C}_{21} \mathrm{H}_{15} \mathrm{~N}_{5} \mathrm{O}$ : C, 71.38; $\mathrm{H}$, 4.28; N, 19.82. Found: C, 71.16; H, 4.44; N, 19.85. 
24). 6-amino-4-(3-nitrophenyl)-1,4-dihydro-3-methyl1-phenylpyrano[2,3-c]pyrazole-5-carbonitrile (8h)

IR (KBr): 3456, 3363, 2190, $1659 \mathrm{~cm}^{-1}$. ${ }^{1} \mathrm{H}$ NMR $\left(\mathrm{CDCl}_{3}+\mathrm{DMSO}-\mathrm{d}_{6}, 400 \mathrm{MHz}\right): \delta=1.80(\mathrm{~s}, 3 \mathrm{H}), 4.73$ (s, 2H), 6.08 (brs, 2H), 7.23 - 7.67 (m, 7H), 8.03 - 8.09 (m, 2H). ESI-MS $\mathrm{m} / \mathrm{z} 374[\mathrm{M}+\mathrm{H}]^{+}$. Anal calcd for $\mathrm{C}_{20} \mathrm{H}_{15} \mathrm{~N}_{5} \mathrm{O}_{3}$ : C, 64.34; H, 4.05; N, 18.76. Found: C, 64.16; H, 3.93; N, 19.03 .
25). 6-amino-4-(2-chlorophenyl)-1,4-dihydro-3- methyl-1-phenylpyrano[2,3-c]pyrazole-5-carbonitrile (8i) IR (KBr): $\mathrm{cm}^{-1} .{ }^{1} \mathrm{H} \mathrm{NMR}\left(\mathrm{CDCl}_{3}, 400 \mathrm{MHz}\right): \delta=1.81$ (s, 3H), 4.67(brs, 2H), 5.23 (s, 1H), 7.12 - 7.41 (m, 7H), 7.56 (d, J = 8.0 Hz, 2H). ESI-MS m/z 363, $365[\mathrm{M}+\mathrm{H}]^{+}$. Anal calcd for $\mathrm{C}_{20} \mathrm{H}_{15} \mathrm{ClN}_{4} \mathrm{O}$ : C, 66.21; H, 4.17; N, 15.44. Found: C, 65.96; H, 4.06; N, 15.29. 